\title{
Chapter 17 \\ The Economics of Resistance Through an Ethical Lens
}

\author{
Richard D. Smith and Joanna Coast
}

\begin{abstract}
Economics is concerned with the analysis of choice and the efficient use of resources. Markets for antibiotics are heavily affected by their 'public good' nature and the externality that results from their consumption in terms of resistance. The non-excludability and non-rivalry associated with knowledge production in antibiotic development also has implications for the supply of antibiotics. On the demand side there are ethical issues associated with free-riding by consumers, freeriding across nations and free-riding across time. On the supply side, the lack of a pipeline for new antibiotics for the future causes both ethical and economic issues and from both perspectives, efforts should perhaps focus more on alternatives to antibiotics and adjustments to heath care systems to reduce reliance on antibiotics. Indeed, unlike many areas of health care, where economics and ethical perspectives may differ, antimicrobial resistance is a case where the two perspectives align in terms of ensuring efficient and sustainable development and use of this precious resources. All strategies for dealing with resistance should share the same goals of achieving an optimal balance in the use of antimicrobial agents and explicit consideration of the distributional implications.
\end{abstract}

Keywords Economics · Externalities $\cdot$ Public-goods $\cdot$ Free-riding $\cdot$ Discounting

\subsection{Introduction}

Antimicrobial resistance has finally come to the fore on national and international agendas, and is now recognised as a critical threat to public health, modern health systems, and economies (Smith 2015) [Ref: Chap. 1]. Although the broad potential

\author{
R. D. Smith $(\bowtie)$ \\ College of Medicine and Health, University of Exeter, Exeter, UK \\ e-mail: rich.smith@exeter.ac.uk \\ J. Coast \\ Population Health Sciences, Bristol Medical School, University of Bristol, Bristol, UK
}

(C) The Author(s) 2020

E. Jamrozik, M. Selgelid (eds.), Ethics and Drug Resistance: Collective

Responsibility for Global Public Health, Public Health Ethics Analysis 5,

https://doi.org/10.1007/978-3-030-27874-8_17 
impacts of resistance are clear - that less effective treatments means greater morbidity and mortality, more expensive treatments or hospital care, and more time off work - robust evidence on the extent of likely impacts of resistance on population health, health care and economies remains relatively limited and often contentious (Coast et al. 1996, 2002; O'Neill 2014; Smith and Coast 2013; Wilton et al. 2002). Like climate change, this lack of clarity stems from inherent uncertainty; in the case of resistance, relating to uncertainties around the growth path of resistance over time, the functional form of the relationship between resistance and antibiotic use, and estimates of the direct morbidity and mortality impacts attributable to resistance rather than underlying infection or other causes (Cormican and Vellinga 2012; Courvalin 2008).

However, apart from such uncertainties, a significant issue is the nature of the decision- making around the production and consumption of antibiotics. Although an intrinsically biological phenomenon, the conditions promoting, or mitigating against, the development and spread of antimicrobial resistance are shaped by choices that are made by farmers and vets, doctors and patients, industry and governments, amongst others, concerning what antibiotics to produce, purchase and use (Smith 2015). Economics, at its foundation, is concerned with analysing and evaluating such choices: what and why certain choices are made over others; the conditions under which such choices are made, and how different conditions affect those choices; and, crucially, whether these choices are the 'best' ones (that is, whether they are 'efficient' in the sense that no greater benefit could be gained from another choice that was available).

These choices are determined through some sort of 'market', broadly defined as a place (physical or virtual) where goods are traded. In this case, for example, a market is where patients and doctors will determine whether an antibiotic will be prescribed, or where a vet and a farmer agree on a course of action for sick animals. Regardless of whether money changes hands, this is the point where an antibiotic supplier will engage with the consumer. Markets also underpin whether, what and how much a producer may invest in production of antibiotics, and the price that the payer (the consumer or their agent, often governments or insurers in the case of healthcare) will pay.

However, markets for antibiotics are heavily affected by two forces which are important when considering the development of antimicrobial resistance and strategies to reduce resistance. First, there are significant 'public good' attributes to antibiotics that affect use and distribution. This means that markets, left alone, will 'fail'; that is, they will not result in a socially optimal level of either production or consumption of antibiotics (Smith and Coast 2003). Second, there are 'externality' effects - effects not included in the decision to consume - that are important, and again means that, left alone, the market will 'fail' and not result in a social optimum of antibiotic consumption (Coast et al. 1998).

Together, these two forces drive the under- and/or over-use of antibiotics compared to what is optimal from a societal perspective. This creates major issues for economic efficiency, as different choices would improve overall societal welfare, but also for ethics, in the sense that there will be equity impacts that create problems 
of distributive (in)justice in access to antibiotics and in the impact of antimicrobial resistance (Coast and Smith 2015).

This chapter describes the core economic features of antimicrobial resistance the public good and externality forces - through an ethics 'lens', focussing especially on the resultant economic and ethical problems of free-riding in both production and consumption. The chapter begins with outlining the core economic perspective on antimicrobial resistance - the market, public goods and externalities - in more detail. From this basis, the chapter then turns to consider the specific issues related to the demand side and then the supply side, focussing on the ethics of the economics, and reflecting on possible strategies to address resistance. In particular, these sections consider the development of appropriate incentives by governments to address free-riding within countries and the development of appropriate incentives by international agencies to address free-riding across countries. Such incentive mechanisms are evaluated both in terms of their value in addressing the economic market- failure and their ethical implications. The chapter concludes with a brief reflection on antimicrobial resistance as a specific case where economic and ethical concerns converge.

\subsection{Antimicrobial Resistance and 'The Market'}

At its most fundamental, the market for antibiotics seeks to equate demand for them by patients (and farmers or those with pets, although in this chapter we will focus on use in humans only) with supply by providers (doctors, pharmacists or over-thecounter stores for example). Patients demand antibiotics because of the impact they (are believed to have) on a health issue, such as a sore throat or urinary-tract infection. There are well-known problems in the market for healthcare goods and services, including the lack of information held by the patient upon which to decide on whether, or how much, healthcare to demand, the resultant need of the patient to rely on an (in economic terminology) 'agent' (usually a medical professional) to help the patient decide on what to consume, and, often, the separation of the patient from payment through the role of a third-party funder - typically government or insurer (Guiness and Wiseman 2011). Markets in healthcare are, therefore, far from perfect, and thus often subject to government intervention in their provision and/or financing. These problems are also, at least partly, responsible for ethical concerns for distributive justice, as they can leave many individuals with no, or inadequate, access to healthcare. Over time, this has led to increased calls for initiatives to ensure 'universal health coverage'; it is now a major thrust of the World Health Organization and World Bank to deal with general market failures in healthcare and to increase access (World Health Organization 2015), whilst the specific market failures around antimicrobial resistance are dealt with through other agendas, such as the Sustainable Development Goals (Hanefeld et al. 2017). 


\subsubsection{Externalities}

Beyond general issues of failure in healthcare markets, there are two specific features of the market for antibiotics that are significant in considering the generation of antimicrobial resistance, and in establishing policies to contain it (Coast et al. 1998). First, there are externality effects from the consumption of antibiotics. An externality is an effect that is outside of the immediate producer or consumer, and thus does not influence decision-making in the choice about whether to produce or consume that antibiotic. So, for the patient, the direct (expected) benefit of the antibiotic in treating an infection informs his or her decision, as do possible side-effects from taking it, along with any monetary cost associated with its purchase. However, a 'positive externality' that is not generally expected to be taken into account by this patient is the benefit to those individuals who would, in the absence of antibiotics, have been infected by them - that is, there is an external benefit associated with reduced transmission of pathogens. The existence of this positive externality means that, the market will under-provide antibiotics; it might be a good reason for a subsidy or other policy to reduce the private cost to individuals. There is also an ethical issue involved here. There is a responsibility for each individual to consider the impact of their choice about receiving treatment on the wider community - that part of their decision to take treatment should, morally, include consideration of the impact of (reduced) infection on the wider population.

More critically for the discussion here is that there is also a major 'negative' externality from consumption of antibiotics - antimicrobial resistance. It is important to note that this externality is not associated with the production of antibiotics but with their consumption. The effects of antibiotic use, in terms of the sustained effectiveness of that antibiotic for others, or for the same individual in the future, do not influence the costs that must be paid by the patient, nor the benefits to them of taking the antibiotic now. They are therefore unlikely to be considered in the decision to purchase and consume that antibiotic (by either the patient or the health professional acting as their agent). From a societal perspective there is thus an overconsumption of antibiotics. Again, there are distributive issues here around the use of a limited resource knowing that it will generate possible greater ill-health in the future and/or for others.

On balance, the optimal consumption of antibiotics from a societal perspective is a balance of the costs and benefits that accrue directly to the individual concerned, plus these external benefits and costs to society (Coast et al. 1998). In recent years, consensus has been that on balance there is over-consumption - that the private costs and benefits and the positive externality are being severely compromised by not accounting for the negative externality of resistance. Focus has therefore been to see how these external costs of resistance can be internalised in to the decision to consume (in addition to how to increase the supply of effective antibiotics). We look at these strategies - affecting the demand and supply sides respectively - later in this chapter. 


\subsubsection{Public Goods}

Second, there are 'public good' aspects associated with antibiotics [Ref: Chap. 8]. Most goods are what we term as 'private' in nature: their consumption can be withheld until a payment is made in exchange, and once consumed they cannot be consumed again (Woodward and Smith 2003). For example, the consumption of a cake can be withheld from the consumer until the consumer pays the baker a price, and once the consumer has eaten that cake it cannot be eaten again. A private good is therefore considered 'excludable' and 'rival in consumption'. At the other end of the spectrum lie public goods, which are defined as having the opposite characteristics. That is, the benefits, once the good is provided, cannot be restricted and are therefore available to all (i.e. non-excludable), and consumption by one individual does not limit consumption of that same good by others (i.e. non-rival in consumption). A classic example is the service provided by a lighthouse: the warning it provides is available to all who would benefit from it, and one ship's use of it does not limit the ability of other ships to use it. Virtually all public goods are such services or other intangibles, with few, if any, 'commodities' (in the narrow sense of physical objects) meeting these criteria (the exception to this being physical infrastructure, such as sewage systems, which once completed are largely non-rival in consumption, and difficult to exclude people from using).

However, both excludability and rivalry are relative, not absolute, concepts, and there is a scale of both rivalry and excludability. For example, access to public goods in particular may be specific to geography (e.g. conventional television broadcasts, while they broadly satisfy the criteria for a public good, reach only an area defined by the location of transmitters, the strength of signals and topographical constraints) or can be artificially made excludable (such as by using encryption services for satellite broadcasts). These create 'club goods', which are non-rival and are non-excludable to those who can access the 'club', but excludable to those outside of the club. Thus, some people could be (and often are) excluded from the benefits of most theoretically defined public goods through geographic, monetary or administrative prohibition. Similarly, rivalry in consumption may be relative to capacity, particularly in the case of physical infrastructure. For example, if a sewage system has spare capacity its use is non-rival, but as the capacity constraint is approached, its use becomes rivalrous; that person whose use of it causes capacity to be reached has effectively prevented the next person wishing to use it from doing so. Perhaps more usual is that the consumption of a particular good may not prevent others from using it, but simply reduces the benefits available. For example, one person's use of a road does not usually prevent use by others, but the use of the road becomes less beneficial as more and more people use it and the road consequently becomes more congested. This is sometimes termed the 'tragedy of the commons' (Hardin 1968), Chap. 8.

Of key importance, is that 'markets' under-supply public goods. First, nonexcludability means that a price cannot be enforced, leading to 'free-riding' (one person can benefit from the actions of another person without reciprocation) and 
thus there is no incentive for anyone to produce or purchase the good. Second, nonrivalry means that the socially optimal level of consumption is far greater than the level that occurs at the 'market price' (Smith and Coast 2003).

To be clear, antibiotics are not themselves public goods - they can be made excludable, and they are rival in the sense that if I use one dose no one else can use that exact same dose.

However, the knowledge they embody in their development, and the resultant property of reduced infection (bearing in mind the externality properties above) means that they have significant public good attributes associated with them. Once developed, the knowledge required to produce the antibiotic can be made (virtually) freely available as dissemination of it is quick and cheap, and any one firm using it to produce the antibiotic does not prevent another from doing so. We will return to this aspect in the section concerning the supply of antibiotics in light of resistance. It also means that the benefits resulting from the consumption of the antibiotic, of reduced infection, cannot be made excludable - we all benefit from reduced transmission of pathogens - and is non-rival - my benefiting from this reduced risk of infection does not diminish you equally benefitting from it. And vice-versa - the reduced effectiveness of antibiotics due to resistance is also non-rival and nonexcludable. It is this consumption side to which we now turn.

\subsection{The Ethics and Economics of Demand}

The characteristics of non-excludability and non-rivalry have important implications for the economics and ethics of the demand/consumption side of the market for antibiotics from a number of perspectives.

\subsubsection{Free-Riding by Consumers}

Consumers have an incentive to engage in free-riding, meaning that they have no incentive to reduce their own use of antibiotics, but rather to wait for others to do so, Chap. 21. This is perhaps also seen as morally acceptable as each individual consumption of each individual course of antibiotics will only add infinitesimally to the problem of resistance; an individual's personal consumption of antibiotics really is a 'drop in the ocean' relative to the total consumption of antimicrobials (Smith and Coast 2013). There are strong parallels here with climate change of course. Overall, the antimicrobial resistance problem is the accumulation of many millions of decisions by different decision makers for different patients in different health systems and facing different personal, financial and organizational incentives. Economic policies in general aim to induce consumers to internalize the costs of any negative externality, but because of the huge diffusion of the problem in relation to resistance, such policies may be very challenging if even possible at all. 
For example, system interventions to address free-riding include taxation (akin to Pigovian taxes or pollution charges in the case of climate change), subsidy, permits or regulation (Coast et al. 1998; Laxminarayan et al. 2010; Smith and Coast 1998) although each of these would have their own distributional implications (Coast and Smith 2015), Chap. 8. Examples of clinical interventions that may address this issue may include better diagnostics (Kolmos and Little 1999; Oppong et al. 2013; Rice 2011) or educational campaigns providing better information (Goossens et al. 2006; Huttner et al. 2010), combined with a gatekeeping role from healthcare providers. Other possibilities include focussing more on assessing option or existence value (the idea that individuals have some personal utility from knowing that the option for them to consume antimicrobials in the future will be retained) (Coast et al. 2006). However, it is more likely that benefits may come from encouraging a greater moral responsibility to avoid resistance within society, such as has been undertaken with climate change and pollution, or as a parallel to stronger regulations, such as with banning smoking in public places, compulsory wearing of seatbelts in cars or drink-driving campaigns.

\subsubsection{Free-Riding Across Nations}

These issues of individual free-riding are also paralleled by free-riding across macro-settings. Actions taken by current patients have the potential to transmit resistance, through the pathogen this resistance is associated with, across international, cultural and ethnic boundaries. Antimicrobial resistance does not respect regional or national boundaries, with resistant organisms being able to travel from one setting to another just as easily as sensitive ones (Smith and Coast 2002). Globalization has increased the rate at which infectious diseases can travel, and resistances identified in one area are rapidly found in other countries and on other continents. Such spread will be dependent on many epidemiological factors, including for example, socio-demographic factors, density of the population, natural disasters, hygiene levels and so on. Areas with greater poverty may be particularly susceptible to the rapid spread of infection and thus the deleterious effects of resistance.

Transmission of resistance may have particularly severe consequences for economies which already suffer greatly from infectious disease - countries where living conditions are poor and where there are high proportions of individuals with immune-compromise - but it will also have significant economic and health consequences at a global level (Smith and Coast 2002).

Indeed, transmission of resistance across national boundaries compromises measures that individual countries may put in place to try to combat resistance; importing resistance from elsewhere may negate national initiatives, rendering them effectively pointless. Conversely, countries may do little to address resistance within their own borders, relying on the activities of other countries to reduce levels of resistance that come in and out of the country; effectively, individual countries may 
'free-ride' on the actions of the wider global community and the containment policies operated in other settings. The potential for resistance to spread across boundaries reduces the incentive for any single country to act against resistance - either because it will appear futile in the face of a global rise in resistance, or because the optimal approach is to await every other country to act first - which means that none will.

The total effort devoted to containing antimicrobial resistance is thus likely to be suboptimal because some nations will rely on the efforts of other nations. This dilemma facing the creation of collective action against antimicrobial resistance at the global level has been highlighted elsewhere (Årdal et al. 2016; Smith and Coast 2002), although it has recently been suggested that international law may provide a means of dealing with the problem of collective action in this context (Hoffman et al. 2015a; Walls and Ooms 2017), Chaps. 24 and 25.

Despite the importance of the global issue in this context, economic (and other) assessments tend to be conducted on a national basis as if systems are closed to the outside world. Opening this up would promote awareness that it is in national selfinterest to look to address resistance in other countries, and thus contribute to global initiatives, as well as be open to moral arguments, such as those that drive considerable development funds each year from developed to less developed nations (Molzon et al. 2011).

\subsubsection{Time Preference and Discounting: Free-Riding Across Time}

The externality effect is also inter-generational, generating significant issues of inter- generational as well as regional equity. Actions taken by current patients will impact on the transmission and emergence of resistance for future generations, but with similar lack of incentive for either individual consumers or nation states to fully account for the impact of their decisions on others.

The relevant economic concept here is that of time-preference and discounting that people place higher weight on benefits that occur now and costs that occur in the future, thus biasing decisions and choices against future generations (even including themselves in that future generation). The discount rate is the amount at which future years are 'discounted', where a rate of 0 would give equal weight to the current and any future year, and $100 \%$ would give total weight to the current year and count future years as worthless. Thus, a higher rate places more weight on the present. Empirical literature finds huge variance in expressed discount rates, but this is overwhelmingly based on personal perspectives (Asenso-Boadi et al. 2008). These, typically high, rates are not consistent with the normative arguments that are considered when intergenerational equity is discussed, and less weighting explicitly given to current generations (Olsen and Richardson 2013; Richardson and McKie 2007). The authors have also previously noted that discount rates with respect to 
antimicrobial resistance "should reflect collective value judgements and moral issues, rather than just the preference that individuals have for their own consumption over time" (Coast et al. 1996). This is important as high discount rates would result in an almost exclusive focus on the current population, and would probably also mean that the focus would be on interventions intended to reduce transmission of antimicrobial resistance, which has relatively short-term gains, rather than interventions intended to reduce emergence of new resistances, which may be further down the line (but where the total benefits in the absence of discounting may be much greater). This issue is examined in greater detail elsewhere (Coast et al. 2002).

\subsubsection{The Importance of Context}

On the consumption side, therefore, the focus of policy is on incentives and systems to influence demand through education of patients, restriction of availability through regulation, or greater guidance to providers (Dar et al. 2016). There are huge challenges in this respect, not only of construction, enforcement and evaluation of any single policy, but also across contexts. Policy in most developed countries is concerned with reducing the over-use of antibiotics - their use where there is little or no clinical indication, such as for the common cold, their use where there is marginal clinical benefit (e.g. many minor infections in otherwise healthy people, which may hasten their cure by a few days only) and even use where there may be greater morbidity but the disease is not fatal. In contrast in many low- and middle-income countries the challenges are to increase use, where appropriate, to reduce pools of infection, and to reduce practices of dose splitting, use of sub-standard, out-of-date or counterfeit medicines, and cross use of antibiotics for humans and animals (Review on antimicrobial resistance 2015a).

\subsection{The Ethics and Economics of Supply}

Externality and public good aspects are not only relevant to consumers, but also to the producers of antibiotics. The supply-chain of antibiotics is long - from original discovery, research and development, which may be in universities, through testing and eventual production by a pharmaceutical company, through wholesalers, health systems or private pharmacy and retailers (with prospects for counterfeit or substandard antibiotics being introduced along the way), Chap. 5 However, critical to this discussion is the core discovery, development and production of the antibiotics; especially that undertaken in the private sector.

It has been noted many times that there has been a distinctly dry pipeline for new antibiotics over recent decades, with no new class of antibiotic being discovered for many years and declining investment by the pharmaceutical industry in the area of anti-infectives (Cormican and Vellinga 2012). What underlies this is the current 
business model for the development of pharmaceuticals, which is based on a market response to 'free-riding' (Smith et al. 2009).

\subsubsection{Free-Riding and Intellectual Property}

Basic research and development of new drugs is hugely expensive, but the information that is produced from this research and development activity - such as the chemical formulation of a new antibiotic - is almost costless to disseminate, is very hard (especially in the internet age) to exclude other companies having access to, and is non-rival in the sense that me using this information to produce the drug does not prevent you also using the information to produce the drug. Thus, given the nonexcludability of this information, it is socially optimal to encourage wide dissemination and use of it, which can be achieved at almost zero cost once produced. But, the inability to exclude means that a high-price cannot be charged for it to recoup the original investment in its production, and so other producers can 'free-ride' on the back of the one who first produced the information. Since the original producers cannot recoup their costs, let alone gain a profit, then there is no incentive for that information to be produced. Hence, left to this pure market system, there would be no medicines developed (Smith and Coast 2003).

The 'solution' to this situation has been to develop an artificial exclusion system to enable the original producer who discovers and develops the information to charge a higher price to compensate for the research and development costs incurred. This is the 'Intellectual Property Right' system, which in the case of pharmaceuticals is operationalised through a patent (Smith et al. 2009). This system confers a legal exclusion to be placed on others using material that is patented for a specified number of years - usually 20-30. During this time whoever filed the patent, such as the pharmaceutical company, has exclusive rights to use it and can therefore charge a sufficiently high price for the medicine it develops from it to allow it to recoup the costs invested, and to make a profit (Yamabhai and Smith 2015).

This 'solution', however, creates a critical problem for both efficiency and ethics. Due to the non-rival nature of the information - and the non-rival nature of the resultant reduction in infectious disease risk from taking the antibiotic that is based on the information - it is most socially efficient if it is widely disseminated and used. The patent system creates a restriction on that use, since only those who can afford to pay the price now charged can access it, which will be at a level lower than is socially optimal. Ethically, it also means that the information - and resultant antibiotics - are only available at a much higher price than the production cost, with the known consequence that there will be people who can benefit who are being denied that treatment (Mendelson et al. 2016). The 'patent wedge' between cost price and the price charged by the patent holder can typically by seen when the patent period expires and 'generic' versions of branded pharmaceuticals are made available, which are often hundreds of times cheaper (Smith et al. 2009). During the patent period there are clearly therefore poorer people, and countries, that are not able to 
afford to access these drugs and where ill-health is suffered as a result. For example, the most infamous case is that relating to anti-retroviral therapies for HIV/AIDS which were priced at over US $\$ 10,000$ per person per year by those producing branded products, but could be produced by generic manufacturers for US\$365 per patient per year (Keppler 2013). This is both inefficient and unethical (Laxminarayan et al. 2016). Inequality in access due to price - especially for those in low-income settings - has been the cause of considerable debate more widely with respect to medicines (Trouiller et al. 2002).

There is added complexity in the case of antibiotics, compared to other medicines, in part due to the nature of antibiotics, which are relatively inexpensive compared to other drugs that could be developed and are used for short periods of time (thus reducing the potential profit), and in part due to the development of resistance, as polices elsewhere seek to reduce and restrict use. This is especially the case in high-income countries, which is where the major markets for new antibiotics are based and where companies expect to be able to charge the higher-prices required to support research and development. The combination then of the high development cost, with reduced market volume, has discouraged investment in this area.

\subsubsection{Alternative Systems}

Over the years there have been growing calls for changes to the patent system as underpinning research and development in pharmaceutical in general, largely from those concerned about the bias towards health needs of high-income countries who are the major markets, resulting in concerns around 'neglected diseases' (Trouiller et al. 2002), Chap. 10. More recently, especially following the report from the Independent Review on Antimicrobial Resistance, chaired by Lord Jim O'Neill, there has been a renewed push for the development of new systems for incentivising investment in new antibiotics, where high-income countries too have considerable need that is not being met (Review on antimicrobial resistance 2015a).

One popular alternative is the de-linking of profitability from sales volumes (Brogan and Mossialos 2016; Review on antimicrobial resistance 2015b; Wise 2015). For example, pre- purchase agreements could be made by governments to guarantee the pharmaceutical company a minimum 'market' in terms of sales, but then the government can choose whether and how those drugs would be disseminated. This builds on other recent work, such as by Chatham House, a think-tank on international affairs, which has outlined alternative business models to similarly change the current financial models for encouraging and supporting research and development in new antibiotics (Kesselheim and Outterson 2010; Outterson 2014; Outterson et al. 2015). There is a lot of work and funding also now going in to research and development by governments themselves to directly develop new antibiotics. For example, The U.S. granted GlaxoSmithKline US\$200 million for investment in new antibiotic research and development (GlaxoSmithKline 2013). There are also other initiatives. In the United States for instance there has been an 
extension to marketing exclusivity, accelerated review, and a relaxation of requirements for approval by the Food and Drug Administration (Hatch 2015). Although this leniency may have increased the development and launch of new antibiotics, there is worrying evidence that such 'fast tracking' may generate considerable adverse effects (Doshi 2015).

Critical, of course, is the basic fact that because resistance to an antibiotic begins as soon as it is developed, new agents can never be the sole solution-and are unlikely to be the most cost-effective or sustainable, Chap. 19. Thus, in addition to looking at encouragement of new drug discovery, another focus has been on initiatives to support the sustainable use of current antibiotics through the development of rapid diagnostic tests to support the more 'appropriate' use of antibiotics (Review on antimicrobial resistance 2015a). In the UK there have been specific funds made available to support diagnostics research and development through the UK Research Councils (Medical Research Council 2014), and the Longitude Prize, where $£ 1 \mathrm{~m}$ is to be awarded to whoever first develops a specific rapid - and affordable - diagnostic tool (Nesta 2014). The critical issue here is the last one - affordability. Diagnostic tests face a challenge of affordability in relation to the option to simply take the currently cheaper - antibiotic. The cost of the test relative to the cost of the antibiotic is critical - if the test costs more than, or even approximates, the antibiotic cost then it is likely to be rational for individuals to simply take the antibiotic and risk it not working - if it does work they save the cost of the test, if it does not work then they may need another drug but have still saved the cost of the test, whereas if they have the test and don't need an antibiotic they may have incurred a cost greater than that of simply taking the antibiotic, and if the test suggests they do need that antibiotic all they have done is add a cost of the test on to what they would have paid in any case. There are challenges especially for this in community settings, rather than hospitals, and in low- and middle-income countries.

Given that a critical feature of antimicrobial resistance is that it occurs naturally for all antibiotics, developing new drugs may win successive battles but not the war. It is possible that genomic developments may produce antibiotics where resistance is not seen, or new ways to tackle pathogens. However, in the absence of those, the most serious issue is not, perhaps, systems for encouraging development in new technologies, but rather how to design health systems that are less reliant on antibiotics. Modern healthcare especially, has been built on the basis that infections can be prevented or treated easily and cheaply. Healthcare has become increasingly technological and invasive, and antibiotics have become integrated in many aspects of care, from prevention of iatrogenic infection in surgery, to women delivering by caesarean section to those having cancer treatment (Smith 2015). From both economic and ethical perspectives efforts should perhaps focus more on alternatives to antibiotics and on adjustments to health systems and care pathways to reduce reliance upon antibiotics. 


\subsection{Discussion: The Convergence of Ethics and Economics}

Far from the 'dismal science', or the often perceived amoral (if not immoral) nature of economics being in conflict with ethics, antimicrobial resistance is a case where the two perspectives are frequently aligned. Many of the economic imperatives for ensuring the efficient and sustainable development and use of antibiotics are in-line with major ethical principles to secure benefits that are equitably available and distributed. In this sense, from an economic and ethical perspective, we are seeking to:

- Develop alternative systems to support the discovery, development and production of new antibiotics that are effective for all major infectious diseases globally

- Ensure that these antibiotics are available to those populations that would benefit from them, wherever they are in the world

- Look for alternatives to reduce reliance on antibiotics - alternatives for the same treatment or prevention of infection, and alternatives to avoid infection and risk of infection and hence requirement for antibiotics or their substitutes

It is also important to note that, at least from an economics perspective, the 'eradication' of resistance is not necessarily a desirable goal. To eradicate resistance entirely - or even to maintain resistance at current levels - would require significant, if not total, reduction in the use of antibiotics, as the use of any antibiotic will lead to the development of some resistance.

Such a goal would imply allowing significant mortality and morbidity to be incurred - far in excess of that caused by the resistance itself. The aim must therefore be to use the available strategies to optimise the balance between the current use of effective antibiotics to treat infection, and thus reduce morbidity and mortality today, and minimising the emergence and spread of resistance to these antibiotics and the consequent increased future morbidity and mortality. This balance depends upon the relative costs and benefits of the positive and negative effects involved. It is determining this balance that is critical, and requires consideration from both an economics and an ethical perspective, as it encompasses significant inter-generational and inter-regional distributional aspects.

Given the diverse contexts of the developed and developing nations, it is likely that optimal strategies will vary considerably across these them, but all strategies should share the same goals of achieving an optimal balance in the use of antimicrobial agents (Hoffman et al. 2015b; Woolhouse and Farrar 2014) and explicit consideration of the distributional implications. 


\section{References}

Årdal, C., K. Outterson, S.J. Hoffman, A. Ghafur, M. Sharland, N. Ranganathan, et al. 2016. International cooperation to improve access to and sustain effectiveness of antimicrobials. The Lancet 387 (10015): 296-307.

Asenso-Boadi, F., T.J. Peters, and J. Coast. 2008. Exploring differences in empirical time preference rates for health: An application of meta-regression. Health Economics 17: 235-248.

Brogan, D.M., and E. Mossialos. 2016. Systems, not pills: The options market for antibiotics seeks to rejuvenate the antibiotic pipeline. Social Science \& Medicine 151: 167-172.

Coast, J., and R.D. Smith. 2015. Distributional considerations in economic responses to antimicrobial resistance. Public Health Ethics 8 (3): 225-237.

Coast, J., R.D. Smith, and M.R. Millar. 1996. Superbugs: Should antimicrobial resistance be included as a cost in economic evaluation? Health Economics 5: 217-226.

1998. An economic perspective on policy to reduce antimicrobial resistance. Social Science and Medicine 46 (1): 29-38.

Coast, J., R.D. Smith, P. Wilton, A.M. Karcher, and M.R. Millar. 2002. Superbugs II: How should economic evaluation be conducted for interventions which aim to reduce antimicrobial resistance? Health Economics 11 (7).

Coast, J., R.D. Smith, and M.R. Millar. 2006. Disentangling value: Assessing the benefits of containing antimicrobial resistance. In The economics of infectious disease, ed. J.A. Roberts, 201-214. Oxford: Oxford University Press. (Reprinted from: In File).

Cormican, M., and A. Vellinga. 2012. Existing classes of antibiotics are probably the best we will ever have. British Medical Journal 344: e3369.

Courvalin, P. 2008. Predictable and unpredictable evolution of antibiotic resistance. Journal of Internal Medicine 264 (1): 4-16.

Dar, O.A., R. Hasan, J. Schlundt, S. Harbarth, G. Caleo, F.K. Dar, et al. 2016. Exploring the evidence base for national and regional policy interventions to combat resistance. The Lancet 387 (10015): 285-295.

Doshi, P. 2015. Speeding new antibiotics to market: A fake fix? BMJ: British Medical Journal 350: h1453.

GlaxoSmithKline. 2013. GlaxoSmithKline awarded up to $\$ 200$ million by U.S. Government to develop new antibiotics. Middlesex: GlaxoSmithKline.

Goossens, H., D. Guillemot, M. Ferech, B. Schlemmer, M. Costers, M. Van Breda, L.J. Baker, et al. 2006. National campaigns to improve antibiotic use. European Journal of Clincal Pharmacology 62: 373-379.

Guiness, L., and V. Wiseman. 2011. Introduction to health economics. 2nd ed. Maidenhead: McGraw-Hill Education.

Hanefeld, J., M. Khan, G. Tomson, and R. Smith. 2017. Trade is central to achieving the sustainable development goals: A case study of antimicrobial resistance. BMJ 358: j3505.

Hardin, G. 1968. The tragedy of the commons. Science 162 (3859): 1243-1248.

Hatch, O. 2015. Promise for antibiotics and therapeutics for health act or the PATH act. In. www. congress.gov/bill/114th-congress/senate-bill/185?q $=\% 7 \mathrm{~B} \% 22$ search $\% 22 \% 3 \mathrm{~A} \% 5 \mathrm{~B} \% 22 \mathrm{~s} .1$ $85 \% 22 \% 5 \mathrm{D} \% 7 \mathrm{D}$.

Hoffman, S.J., K. Outterson, J.-A. Røttingen, O. Cars, C. Clift, Z. Rizvi, et al. 2015a. An international legal framework to address antimicrobial resistance. Bulletin of the World Health Organization 93 (2): 66-66.

Hoffman, S.J., J.-A. Røttingen, and J. Frenk. 2015b. Assessing proposals for new global health treaties: An analytic framework. American Journal of Public Health 105 (8): 1523-1530.

Huttner, B., H. Goossens, T. Verheij, and S. Harbarth. 2010. Characteristics and outcomes of public campaigns aimed at improving the use of antibiotics in outpatients in high- income countries. Lancet Infectious Diseases 10: 17-31.

Keppler, H. 2013. The untold AIDS story: How access to antiretroviral drugs was obstruced in Africa. 
Kesselheim, A.S., and K. Outterson. 2010. Fighting antibiotic resistance: Marrying new financial incentives to meeting public health goals. Health Affairs 29 (9): 1689-1696.

Kolmos, H.J., and P. Little. 1999. Should general practitioners perform diagnostic tests on patients before prescribing antibiotics? British Medical Journal 318: 799-802.

Laxminarayan, R., I.W.H. Parry, D.L. Smith, and E.Y. Klein. 2010. Should new antimalarial drugs be subsidized? Journal of Health Economics 29: 445-456.

Laxminarayan, R., P. Matsoso, S. Pant, C. Brower, J.-A. Røttingen, K. Klugman, and S. Davies. 2016. Access to effective antimicrobials: A worldwide challenge. The Lancet 387 (10014): $168-175$.

Medical Research Council. 2014. Tackling AMR theme 2: Accelerating therapeutic and diagnostics development EOI. In. www.mrc.ac.uk/funding/browse/ tackling-amr-theme-2-accelerating-therapeutic-and-diagnostics-development-eoi.

Mendelson, M., J.-A. Røttingen, U. Gopinathan, D.H. Hamer, H. Wertheim, B. Basnyat, et al. 2016. Maximising access to achieve appropriate human antimicrobial use in low-income and middle-income countries. The Lancet 387 (10014): 188-198.

Molzon, J.A., A. Giaquinto, L. Lindstrom, T. Tominaga, M. Ward, P. Doerr, et al. 2011. The value and benefits of the international conference on harmonisation to drug regulatory authorities: Advancing harmonization for better public health. Clinical Pharmacology \& Therapeutics 89 (4): 503-512.

Nesta. 2014. The challenge: Reduce the use of antibiotics. In. https://longitudeprize.org/challenge.

O'Neill, J. 2014. Review on antimicrobial resistance. Antimicrobial resistance: Tackling a crisis for the health and wealth of nations. London: HM Government; Wellcome Trust.

Olsen, J.A., and J. Richardson. 2013. Preferences for the normative basis of health care priority setting: Some evidence from two countries. Health Economics 22 (4): 480-485.

Oppong, R., M. Jit, R.D. Smith, C.C. Butler, H. Melbye, S. Molstad, and J. Coast. 2013. Costeffectiveness of point-of-care C-reactive protein testing to inform antibiotic prescribing decisions. British Journal of General Practice 63 (612): e465-e471.

Outterson, K. 2014. New business models for sustainable antibiotics. London: Chatham House.

Outterson, K., J.H. Powers, G.W. Daniel, and M.B. McClellan. 2015. Repairing the broken market for antibiotic innovation. Health Affairs 34 (2): 277-285.

Review on antimicrobial resistance. 2015a. Tackling a global health crisis: Initial steps.

2015b. Securing new drugs for future generations: The pipeline of antibiotics.

Rice, L.B. 2011. Rapid diagnostics and appropriate antibiotic use. Clinical Infectious Diseases 52 (Suppl 4): S357-S360.

Richardson, J., and J. McKie. 2007. Economics, political philosophy and ethics: The role of public preferences in health care decision-making. In Principles of health care ethics, 2 nd ed., 569-576.

Smith, R. 2015. Antimicrobial resistance is a social problem requiring a social solution. BMJ: British Medical Journal 350: h1453.

Smith, R.D., and J. Coast. 1998. Controlling antimicrobial resistance: A proposed transferable permit market. Health Policy 43: 219-232.

- 2002. Antimicrobial resistance: a global response. Bulletin of the World Health Organization 80: 126-133.

2003. Antimicrobial drug resistance. In Global public goods for health: A health economic and public health perspective, ed. R.D. Smith, R. Beaglehole, D. Woodward, and N. Drager. Oxford: Oxford University Press.

Smith, R., and J. Coast. 2013. The true cost of antimicrobial resistance. BMJ 346 (f1493): 1-5.

Smith, R.D., C. Carlos, and O. Cecilia. 2009. Trade, TRIPS, and pharmaceuticals. Lancet 373 (9664): 684-691.

Trouiller, P., P. Olliaro, E. Torreele, J. Orbinski, R. Laing, and N. Ford. 2002. Drug development for neglected diseases: A deficient market and a public-health policy failure. The Lancet 359 (9324): 2188-2194. 
Walls, H.L., and G. Ooms. 2017. Innovative use of the law to address complex global health problems: Comment on the legal strength of international health instruments-what it brings to global health governance? International Journal of Health Policy Management 6.

Wilton, P., R.D. Smith, J. Coast, and M.R. Millar. 2002. Strategies to contain the emergence of antimicrobial resistance: A systematic review of effectiveness and cost- effectiveness. Journal of Health Services Research and Policy 7: 111-117.

Wise, J. 2015. Report calls for \$2 bn global fund to kickstart antibiotic development. BMJ: British Medical Journal 350: h2635.

Woodward, D., and R.D. Smith. 2003. Global public goods for health: Concepts and issues. In Global public goods for health: A health economic and public health perspective, ed. R.D. Smith, R. Beaglehole, D. Woodward, and N. Drager. Oxford: Oxford University Press.

Woolhouse, M., and J. Farrar. 2014. Policy: An intergovernmental panel on antimicrobial resistance. Nature 509 (7502): 555-557.

World Health Organization. 2015. Tracking universal health coverage: First global monitoring report. Geneva: World Health Organization.

Yamabhai, I., and R.D. Smith. 2015. To what extent are pharmaceutical prices determined by patents? A case study of oncology medicines in Thailand. Journal of Intellectual Property Rights 20: 89-95.

Open Access This chapter is licensed under the terms of the Creative Commons Attribution 4.0 International License (http://creativecommons.org/licenses/by/4.0/), which permits use, sharing, adaptation, distribution and reproduction in any medium or format, as long as you give appropriate credit to the original author(s) and the source, provide a link to the Creative Commons licence and indicate if changes were made.

The images or other third party material in this chapter are included in the chapter's Creative Commons licence, unless indicated otherwise in a credit line to the material. If material is not included in the chapter's Creative Commons licence and your intended use is not permitted by statutory regulation or exceeds the permitted use, you will need to obtain permission directly from the copyright holder.

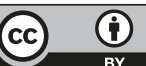

